\title{
PROBLEM BASED LEARNING, KEMAMPUAN BERPIKIR KRITIS, KERJASAMA DAN HASIL BELAJAR SISWA SMP
}

\author{
Yohana Febriana Tabun1 Widha Sunarno2 Sukarmin3 \\ 1 Mahasiswa Magister Pendidikan Sains, Universitas Sebelas Maret Surakarta \\ 2 Dosen Pendidikan Fisika, Universitas Sebelas Maret Surakarta \\ 3 Dosen Pendidikan Fisika, Universitas Sebelas Maret Surakarta \\ *Coresponding author: yohanatabun96@student.uns.ac.id
}

\section{A R T I CLE INFO}

Article history:

Received: 24 Mei 2019

Accepted: 12 September 2019

\section{Keywords:}

Problem Based Learning (PBL), critical thinking ability, collaboration, learning outcome

\begin{abstract}
ABSTRAK
The research sets to examine the influence of Problem Based Learning (PBL), critical thinking ability, and collaboration toward learning outcome of Christian Junior High School (SMPK) Stelamaris Biudukfoho. Quasi experiment using non-equivalent control group design is employed in this research. The first and the second experiment group are selected based on assignment random sampling. There are 60 subjects at the eighth grade of Junior High School in the academic year of 2018/2019. The researchers apply test to measure critical thinking ability and learning outcome, whereas questionnaire is employed to measure collaboration of the students. The data analysis is three-way analysis of variance. The results reveal that there is significant differentiation of learning outcome between a group using PBL and a group using conventional method, between the students with high and low critical thinking ability, between the students with high and low collaboration. In addition, there is significant interaction of learning model, critical thinking ability, and collaboration toward students' learning outcome. It means that students' learning outcome depends on the learning model, critical thinking ability, and collaboration of the students.
\end{abstract}

\section{PENDAHULUAN}

Pembelajaran yang sesuai dengan tujuan kurikulum 2013 adalah pembelajaran berpusat pada siswa atau student center (Djamahar, Ristanto, Sartono, Ichsan, \& Muhlisin, 2018). Namun, penerapan kurikulum 2013 belum sepenuhnya di jalankan sesuai dengan tujuannya. Hal ini di karenakan guru di sekolah-sekolah masih banyak yang menerapkan metode ceramah yang diselingi tanya jawab. yang bersifat teacher center (berpusat pada guru). Metode ceramah ini membuat siswa tidak aktif dalam 
pembelajaran. Disamping itu, metode ceramah membuat siswa tidak dapat memahami konsep IPA.

Pembelajaran IPA merupakan suatu proses belajar mengajar yang mempelajari peristiwa dan gejala-gejala yang terjadi di alam semesta yang bertujuan meningkatkan kemampuan pengetahuan, keterampilan, dan sikap yang dikembangkan melalui pengalaman belajar dan eksperimen ataupun investigasi. Berkaitan dengan hal tersebut, pembelajaran IPA di SMP bertujuan agar siswa mampu menguasai konsep-konsep IPA dengan benar melalui pengalaman belajar dan eksperimen ataupun investigasi, sehingga diperlukan suatu pembelajaran yang berbasis kerangka berpikir guru dengan model pembelajaran untuk menunjang kegiatan pembelajaran di kelas (Yusnaeni, Lika, \& Hiul, 2019).

Berdasarkan hasil observasi dan wawancara di SMPK Stelamaris Biudukfoho pada semester ganjil tahun ajaran 2018/2019 informasi yang diperoleh bahwasannya pembelajaran yang dilakukan masih belum efektif. Penyebab pembelajaran tersebut tidak efektif dikarenakan informasi yang disampaikan oleh guru belum dipahami siswa sehingga siswa cenderung pasif saat pembelajaran. Di kelas, guru sering menggunakan metode ceramah dalam menyampaikan konsep IPA. Penggunaan metode ceramah menempatkan siswa sebagai pendengar dan pencatat serta membuat siswa memiliki keterbatasan kemampuan pada tingkat rendah. Kekurangan dari metode ceramah adalah penguasaan materi oleh siswa akan terbatas pada yang dikuasai guru, guru sulit mengetahui apakah siswa sudah paham apa yang diajarkan atau belum (Wina, 2006). Bila guru memiliki kemampuan bertutur yang kurang baik maka metode ceramah akan sangat membosankan. Dari uraian di atas, menyebabkan pengetahuan yang diperoleh siswa tidak maksimal. Dengan demikian model pembelajaran yang bisa membuat pembelajaran lebih bermakna dan dapat memicu keaktifan siswa adalah pembelajaran berbasis masalah atau PBL (Problem Based Learning).

Problem Based Learning (PBL) merupakan metode instruksional yang menantang siswa agar "belajar untuk belajar", bekerja sama dalam kelompok untuk mencari solusi bagi permasalahan. Masalah dalam pembelajaran ini digunakan untuk mengaitkan rasa keingintahuan serta kemampuan analisis siswa dan inisiatif dengan materi pelajaran. PBL mempersiapkan siswa untuk berpikir kritis dan analitis, dan untuk men-cari serta menggunakan sumber belajar yang sesuai (Amir, 2009). Karakteristik yang tercakup dalam PBL, antara lain adalah (1) masalah digunakan sebagai awal pembelajaran; (2) masalah membuat siswa tertantang untuk mendapatkan pembelajaran di ranah pembelajaran yang baru; (3) sangat mengutamakan belajar mandiri (self directed learning); dan (4) pembelajarannya kolaboratif, komunikatif, dan kooperatif. Dengan PBL diharapkan siswa belajar berinteraksi dengan kelompok dan saling memberikan informasi kepada sesama anggota kelompok (Pratama, 2018).

Selain memperhatikan model pembelajaran yang digunakan, perlu kiranya memperhatikan kemampuan berpikir kritis siswa, berpikir kritis sangat penting dalam proses kegiatan pembelajaran (Noviyanti, Rusdi, \& Ristanto, 2019). Berpikir kritis merupakan proses berpikir intelektual di mana pemikir dengan sengaja menilai kualitas pemikirannya, pemikir menggunakan pemikiranyang reflektif, independen, jernih, dan rasional (Permana \& Chamisijatin, 2019). Berpikir kritis adalah memberdayakan keterampilan atau strategi kognitif dalam menentukan tujuan (Achmad, 2007; Bustami, Riyati, \& Julung, 2019). Proses tersebut dilalui setelah menentukan tujuan, mempertimbangkan, dan mengacu langsung kepada sasaran-merupakan bentuk berpikir yang perlu dikembangkan dalam rangka memecahkan masalah, merumuskan kesimpulan, mengumpulkan berbagai kemungkinan, dan membuat keputusan ketika menggunakan semua keterampilan tersebut secara efektif dalam konteks dan tipe yang tepat.

Disamping model pembelajaran dan kemampuan berpikir kritis siswa, perlu diperhatikan tentang kerjasama siswa. Salah satu unsur agar tujuan pembelajaran dapat 
tercapai yaitu dengan adanya kerjasama. Bekerja sama akan membuat seseorang mampu melakukan lebih banyak hal daripada bekerja sendirian (Nurnawati, Yulianti, dan Susanto, 2012: 2). Riset membuktikan bahwa pada bidang aktivitas dan upaya manusia, jika dilakukan dengan kerjasama secara kelompok, maka akan mengarah pada efisiensi dan efektivitas yang lebih baik (West dalam Nurnawati, Yulianti, dan Susanto, 2012: 2).

Tujuan penelitian ini adalah untuk menguji pengaruh model PBL sebagai variabel bebas, dan kemampuan berpikir kritis serta kerjasama sebagai variabel moderator terhadap hasil belajar sebagai variabel terikat. Pengaruh tersebut dapat dilihat dari adanya perbedaan rerata perolehan hasil belajar dalam kelompok eksperimen dibandingkan dengan kelompok kontrol.

\section{METODE}

Penelitian ini adalah penelitian kuasi eksperimen untuk mengungkap hubungan sebab-akibat dengan cara melibatkan kelompok kontrol di samping kelom-pok eksperimental (Ibnu dkk., 2003). Penelitian ini menggunakan rancangan Nonequivalent Control Group Design dengan pertimbangan bahwa penentuan ke-lompok eksperimen dan kelompok kontrol tidak dapat dilakukan dengan rambang individu, tetapi dilakukan dengan rambang kelompok (assigment random sam-pling) yaitu pada kelas VIII A dan VIII B. Penggunaan random assigment ditempuh berdasarkan pertimbangan bahwa tidak mungkin dilakukan pemilih-an kelompok eksperimen dan kelompok kontrol de-ngan rambang terhadap subjek dalam penelitian ini (Mukhadis, 2003). Rancangan penelitian ini menggunakan pola faktorial design $2 \times 2 \times 2$, menyediakan peluang untuk menentukan pengaruh-pengaruh utama (main effects) dan pengaruh-pengaruh interaktif (interactive effects) dari variabel-variabel perlakuan. Pengaruh-pengaruh utama variabel perlakuan meliputi variabel model pembelajaran PBL dan pengaruh variabel pembelajaran konvensional.

Penelitian ini dilaksanakan pada siswa Kelas VIII Tahun Pelajaran 2018/2019. Subjek penelitian berjumlah siswa yang terbagi atas 30 siswa kelas eksperimen dan 30 siswa kelas kontrol. Instrumen yang digunakan ada dua yaitu nontes dan tes. Instrumen yang berupa nontes digunakan untuk memperoleh data kerjasama siswa, sementara instrumen yang berupa tes digunakan untuk memperoleh data kemampuan berpikir kritis dan hasil belajar siswa.

\section{HASIL DAN PEMBAHASAN}

Penelitian ini menggunakan kelas VIII A sebagai kelas eksperimen dan kelas VIII B sebagai kelas kontrol. Hasil penelitian yang berupa rerata hasil tes pada masing-masing kelompok siswa dengan skor kemampuan berpikir kritis dan kerjasama baik pada kelas perlakuan (PBL) maupun pada kelas kontrol (konvensional) disajikan pada Tabel 1. Hasil analisis varian (Univariate-Analysis of Variance) menggunakan SPSS versi 16.0 dengan taraf kepercayaan 5\% $(\alpha=0,05)$, terhadap data hasil penelitian, disajikan pada Tabel 2. Berdasarkan data dan analisis, diuraikan pembahasan secara berurutan sesuai dengan tujuan penelitian ini.

\section{Pengaruh Model PBL terhadap Hasil Belajar}

Pada Tabel 1 dapat dilihat bahwa rerata hasil belajar siswa pada kelompok PBL (tanpa memerhatikan tingkatan kemampuan berpikir kritis dan kerjasama) adalah 77,71 atau lebih tinggi dari rerata hasil belajar kelompok siswa yang mendapatkan pembelajaran secara konvensional dengan rerata sebesar 74,47. Berdasarkan hasil analisis data dapat diinterpretasikan bahwa PBL dilengkapi modul lebih baik dibandingkan dengan pembelajaran konvensional dilengkapi modul. Hasil analisis data (Tabel 2) juga memperkuat hal ini. Pada Tabel 2, sumber (source) "Perlakuan" menunjukkan nilai F = 7,519 dengan signifikansi 0,008 yang lebih kecil dari 0,005, yang berarti bahwa ada 
perbedaan rerata hasil belajar yang disebabkan oleh perlakuan, yaitu jenis model pembelajaran.

Hasil penelitian sebelumnya yang sejalan dengan penelitian ini adalah penelitian Anggraini, dkk., pada tahun 2012 mengemukakan bahwa ada perbedaan hasil belajar yang signifikan terhadap pembelajaran Pemrograman $\mathrm{C}++$ antara kelompok siswa yang diajar dengan PBL dengan kelompok siswa yang diajar dengan model pembelajaran konvensional. Ini berarti pemberian Perlakuan PBL memberikan dampak yang lebih baik terhadap hasil belajar dibandingkan dengan model pembelajaran konvensional.

Menurut Dewanto (2008), PBL juga memberikan kesempatan kepada siswa untuk lebih berani bertanya, menjawab, dan beragumentasi dengan teman sebaya dan pengajarnya. Hal tersebut juga sejalan dengan pendapat Sudarman (2007) yang menyatakan bahwa keuntungan penerapan PBL dalam pembelajaran adalah mendorong kerja sama dalam menyelesaikan tugas. Jadi, keunggulan PBL dibanding-kan pembelajaran konvensional adalah bahwa PBL membelajarkan siswa untuk memahami konsep, PBL membelajarkan siswa untuk aktif dan berpikir kritis, dan PBL membelajarkan siswa untuk belajar mandiri dan kerja dalam tim. PBL berfokus pada keaktivan siswa dalam kegiatan pembelajaran. Siswa tidak lagi diberikan materi belajar secara satu arah seperti pada metode pembelajaran konvensional, dan dengan metode ini maka siswa mengembangkan pengetahuannya secara mandiri.

\section{Pengaruh Kemampuan Berpikir Kritis terhadap Hasil Belajar}

Pada Tabel 1 ditunjukkan rerata hasil belajar siswa pada kelompok PBL yang memiliki kemampuan berpikir kritis tinggi $(=81,12)$ lebih tinggi dibandingkan kemampuan berpikir kritis rendah $(=71,06)$. Sementara itu rerata hasil belajar siswa pada kelompok konvensional yang memiliki kemampuan berpikir kritis tinggi $(=71)$ lebih tinggi dibandingkan yang motivasi belajarnya rendah $(=67)$. Hal ini juga diperkuat oleh hasil analisis data (Tabel 2), yang menunjukkan bahwa pada sumber (source) "Kemampuan Berpikir Kritis" menunjukkan bahwa nilai $\mathrm{F}=22,617$ dengan signifikansi 0,000 , yang berarti bahwa ada pengaruh yang signifikan dari kemampuan berpikir kritis terhadap hasil belajar.

Hasil penelitian ini sejalan dengan penelitian Edo Dwi Cahyo (2016) yang mengemukakan bahwa terdapat perbedaan kemampuan berpikir kritis antara siswa yang memperoleh pembelajaran menggunakan metode PBL pada kelas eksperimen dengan siswa yang memperoleh pembelajaran konvensional pada kelas kontrol. Selain itu, anakanak berpikir lebih kritis dengan metode PBL, karena dengan PBL menuntut siswa lebih percaya kepada hasil fakta-fakta pembelajaran yang konkrit dari pada opini publik.

\section{Pengaruh Kerjasama terhadap Hasil Belajar}

Tabel 2 sumber (source) "Kerjasama" menunjukkan bahwa nilai $\mathrm{F}=37,365$ dengan signifikansi $=0,000(\mathrm{p} \leq 0,05)$, yang berarti bahwa ada perbedaan rerata hasil belajar disebabkan oleh faktor ketiga yaitu kerjasama siswa. Pada Tabel 2 rerata hasil belajar siswa pada kelompok PBL yang memiliki kerjasama tinggi $(=82,63)$ lebih tinggi dibandingkan kerjasama rendah $(=70,28)$. Sementara itu rerata hasil belajar siswa pada kelompok konvensional yang memiliki kerjasama tinggi $(=70)$ lebih tinggi dibandingkan rerata hasil belajar siswa yang memiliki kerjasama rendah $(=67,67)$. 
Hasil penelitian ini sejalan dengan hasil penelitian Sucipto (2017:84) bahwa dengan model project based learning siswa dapat berpatisipasi penuh saat pembelajaran, karena model ini dituntut agar dapat mengkonstruk pengetahuan mereka. Setiap anggota kelompok memiliki tanggungjawab masing-masing dalam mengerjakan tugas proyek, sehingga tidak ada yang dianggap menumpang kepada anggota yang lain. Pada penelitian ini siswa dilatih untuk bekerja dengan teman lain. Dominguez (2010) menjelaskan bahwa bekerja dengan oranglain mampu meningkatkan keterlibatan belajar, berbagi ide-ide dan menanggapi reaksi oranglain meningkatkan pemikiran dan pemahaman mendalam. Pada akhirnya dengan menggunakan model project based learning berbantuan metode edutainment dapat meningkatkan kemampuan kerjasama siswa.

Tabel 1. Perbandingan Rerata Hasil Belajar Siswa

\begin{tabular}{|l|l|l|l|l|}
\hline $\begin{array}{l}\text { Kelas } \\
\text { Perlakuan }\end{array}$ & $\begin{array}{l}\text { Kemampuan } \\
\text { Berpikir Kritis }\end{array}$ & Skor Rerata & Kerjasama & Skor Rerata \\
\hline PBL & Rendah & 71,06 & Rendah & 70,28 \\
\hline & Tinggi & 81,12 & Tinggi & 82,63 \\
\hline Konvensional & Rendah & 67 & Rendah & 67,67 \\
\hline & Tinggi & 71 & Tinggi & 70 \\
\hline
\end{tabular}

Tabel 2. Hasil Analisis Varian Variabel

\begin{tabular}{|l|l|l|l|}
\hline \multicolumn{1}{|c|}{ Sumber } & F hitung & \multicolumn{1}{c|}{$\boldsymbol{p}$ value } & \multicolumn{1}{c|}{ Keputusan } \\
\hline $\begin{array}{l}\text { Perlakuan } \\
\text { Kemampuan berpikir } \\
\text { kritis }\end{array}$ & 7,519 & 0,008 & Ada Perbedaan (berpengaruh) \\
Kerjasama & 22,617 & 0,000 & Ada Perbedaan (berpengaruh) \\
\hline
\end{tabular}

\section{KESIMPULAN}

Ada perbedaan hasil belajar yang signifikan terhadap pembelajaran IPA Terpadu antara kelompok siswa yang diajar dengan PBL dengan kelompok siswa yang diajar dengan model pembelajaran konvensional. Ini berarti pemberian Perlakuan PBL memberikan dampak yang lebih baik terhadap hasil belajar dibandingkan dengan model pembelajaran konvensional.

Ada perbedaaan hasil belajar IPA Terpadu yang signifikan antara kelompok siswa yang memiliki kemampuan berpikir kritis tinggi dan rendah. Siswa mendapatkan hasil belajar yang lebih tinggi apabila memiliki kemampuan berpikir kritis tinggi baik pada kelompok PBL. Ini berarti kemampuan berpikir kritis sebagai pendorong usaha dalam pencapaian hasil belajar. Ada perbedaan hasil belajar IPA Terpadu yang signifikan antara kelompok siswa yang memiliki kerjasama tinggi dan rendah. Siswa akan mendapatkan hasil belajar yang lebih tinggi apabila memiliki kerjasama tinggi baik pada kelompok PBL maupun konvensional.

Penelitian ini bersifat quasi eksperimen, oleh sebab itu disarankan kepada peneliti lain untuk mela-kukan penelitian yang lebih mendalam untuk masalah yang sama dengan menerapkan metode penelitian yang lebih mendalam dan menggunakan variabel yang dianggap sangat berpengaruh terhadap hasil belajar siswa, misalnya gaya belajar, sikap dan faktor lain dalam rancangan peneli-ian, sehingga didapatkan hasil yang lebih komprehensif. Penilaian hasil belajar IPA Terpadu dalam penelitian ini hanya mengukur domain pengetahuan sehingga disarankan penelitian selanjutnya dengan mengukur hasil belajar sikap dan keterampilan. 


\section{DAFTAR PUSTAKA}

Achmad, Arief. (2007). Memahami Berpikir Kritis. [online]. Tersedia: http://researchengines.com/1007arief3.html. [2 April 2010]

Amir, T. 2009. Inovasi Pendidikan Melalui Problem Based Learning. Jakarta: Kencana Prenada Media Group.

Anggraini, dkk., 2012, Problem Based Learning, Motivasi Belajar, Kemampuan Awal, Dan Hasil Belajar Siswa SMK: Jurnal Ilmu Pendidikan, Jilid 19, Nomor 2, Desember 2013, hlm. 187-195

Bustami, Y., Riyati, Y., \& Julung, H. (2019). Think talk write with pictured cards on human digestive system: impact of critical thinking skills. Biosfer: Jurnal Pendidikan Biologi, 12(1), 13-23.

Cahyo, Edo Dwi, 2016, Pengaruh Penerapan Metode Problem Based Learning dalam Meningkatkan Pemahaman Konsep Dasar IPS dan Kemampuan Berpikir Kritis Siswa: UPI Bandung

Djamahar, R., Ristanto, R. H., Sartono, N., Ichsan, I. Z., \& Muhlisin, A. (2018). Cirsa: designing instructional kits to empower 21st century skill. Educational Process: International Journal, 7(3), 200-208.

Dominguez, D. 2010. "Principle 2: Good Practice Encourages Cooperation Among Students. Brigham Young University" .Journal of Legal Education, 49: 386-400.

Ibnu, S., Mukhadhis, A., \& Dasna, I.W. 2003. Dasar-Dasar Metodologi Penelitian. Malang: Universitas Negeri Malang.

Mukhadis, A. 2003. Pengorganisasian Isi Pembelajaran Tipe Prosedural: Kajian Empirik pada Latar Se-kolah Menengah Kejuruan Rumpun Teknologi. Di-sertasi tidak diterbitkan. Malang: Universitas Negeri Malang.

Noviyanti, E., Rusdi, R., \& Ristanto, R. H. (2019). Guided Discovery Learning Based on Internet and Self Concept: Enhancing Student's Critical Thinking in Biology. Indonesian Journal of Biology Education, 2(1), 7-14.

Nurnawati, E., Yulianti., dan Susanto. 2012. Peningkatan Kerjasama Siswa SMPMelalui Penerapan Pembelajaran Koope-ratif Pendekatan Think Pair Share.Unnes Physics Education Journal.Vol.1 (1): 1-7.(Online),(http://journal.unnes. ac.id/sju/index.php/upej/article/view/764,diakses padatanggal 8 November 2015; 19.37 WIB).

Permana, F. H., \& Chamisijatin, L. (2019). Project-based learning through edmodo: improving critical thinking and histology concepts. Biosfer: Jurnal Pendidikan Biologi, 12(1), 58-69.

Pratama, A. T. (2018). Improving metacognitive skills using problem based learning (pbl) at natural science of primary school in deli serdang, indonesia. Biosfer: Jurnal Pendidikan Biologi, 11(2), 101-107.

Sanjaya. W. 2006. Strategi Pembelajaran Berorientasi Standar Proses Pendidikan. Jakarta: Kencana.

Sucipto, H. 2017. Penerapan Model Project Based Learning untuk Meningkatkan Minat dan Hasil Belajar IPS. Jurnal Pendidikan: Riset \& Konseptual, .1 (1): 77 - 86.

Yusnaeni, Y., Lika, A. G., \& Hiul, S. (2019). Human respiratory system: designing student worksheet based on inquiry to promote 21 st-century skills. Biosfer: Jurnal Pendidikan Biologi, 12(1), 34-44. 